\title{
Características do gerenciamento de projetos 2.0: um estudo exploratório
}

lasmim Cruz Ribeiro

Bacharel em Engenharia de Software / Universidade Federal de Goiás

Mestre em Administração - Gestão de Projetos / Universidade Nove de Julho- UNINOVE, São Paulo, Brasil

iasmim.cribeiro@gmail.com

Cristiane Drebes Pedron

Professor da Universidade Nove de Julho do Programa de Pós-Graduação em

Administração - PPGA / Programa de Mestrado Profissional em Administração - Gestão de Projetos - UNINOVE, São Paulo, Brasil

cdpedron@gmail.com

Editor Científico: José Edson Lara

Organização Comitê Científico

Double Blind Review pelo SEER/OJS

Recebido em 07.09.2017

Aprovado em 08.03.2018 


\title{
Resumo
}

O gerenciamento de projetos (GP) é a aplicação de conhecimentos, habilidades, ferramentas e técnicas no projeto (PMI, 2013). Contudo, segundo Levitt (2011), um novo composto de métodos, ferramentas e mecanismos de governança surgiu para atender às novas necessidades do mundo moderno. Percebem-se novas tendências devido à globalização, ao crescimento da internet e às inserções das tecnologias de informação (TI) colaborativas, ou seja, das tecnologias da Web 2.0. Portanto, este estudo teve como objetivo identificar quais são as características que devem ser consideradas no gerenciamento de projetos 2.0. Para tanto realizou-se uma pesquisa exploratória e qualitativa, considerando uma revisão sistemática da literatura, um grupo focal e um conjunto de entrevistas com profissionais de gestão de projetos de TI. Obteve-se uma lista de características que compõe o GP 2.0.

Palavras-chave: Gerenciamento de Projetos; Gerenciamento de Projetos 2.0; Web 2.0.

\section{Characteristics of Project Management 2.0: An Exploratory Study}

\begin{abstract}
Project management (PM) is the application of knowledge, skills, tools and techniques in the project (PMI, 2013). However, according to Levitt (2011), a new set of methods, tools and governance mechanisms has emerged to meet the new needs of the modern world. There are new trends due to globalization, the growth of the internet and the insertion of collaborative information technologies (IT), that is, of Web 2.0 technologies. Therefore, this study aimed to identify which characteristics should be considered in project management 2.0. For that, an exploratory and qualitative research was conducted, considering a systematic review of the literature, a focus group and a set of interviews with IT project management professionals. A list of features that make up PM 2.0 was obtained.
\end{abstract}

Keywords: Project Management; Project Management 2.0; Web 2.0.

\section{Características de la Gestión de Proyectos 2.0: Un Estudio Exploratorio}

\section{Resumen}

La gestión de proyectos (GP) es la aplicación de conocimientos, habilidades, herramientas y técnicas en el proyecto (PMI, 2013). Sin embargo, según Levitt (2011), un nuevo compuesto de métodos, herramientas y mecanismos de gobernanza surgió para atender las nuevas necesidades del mundo moderno. Se percibe nuevas tendencias debido a la globalización, el crecimiento de Internet y las inserciones de las tecnologías de información (TI) colaborativas, o sea, de las tecnologías de la Web 2.0. Por lo tanto, este estudio tuvo como objetivo identificar cuáles son las características que deben ser consideradas en la gestión de proyectos 2.0. Para ello se llevó a cabo una investigación exploratoria y cualitativa, considerando una revisión 
sistemática de la literatura, un grupo focal y un conjunto de entrevistas con profesionales de gestión de proyectos de TI. Se ha obtenido una lista de características que compone el GP 2.0.

Palabras-clave: Gestión de Proyectos; Gestión de Proyectos 2.0; Web 2.0.

\section{Introdução}

O gerenciamento de projetos (GP) é a aplicação de conhecimentos, habilidades, ferramentas e técnicas no projeto (PMI, 2013). A realidade e as necessidades dos projetos sofreram alterações ao longo do tempo, exigindo uma avaliação crítica das práticas e conhecimentos convencionais de gerenciamento de projetos prescritas para praticantes, que vivenciam uma forte dependência em relação à visão funcionalista dos projetos e das organizações (Cicmil, Williams, Thomas, \& Hodgson, 2006). Isso ratifica o posicionamento de Shenhar (2004), o qual afirmava que o gerenciamento de projetos do século XXI seria completamente diferente do que tem sido nos últimos cinquenta anos.

Levine (2014) esclarece que a gestão de projetos tradicional tem nos processos os gerentes de projetos controlando todas as entradas e saídas de um projeto promovendo, portanto, um tipo de controle centralizado e hierárquico (Kerzner, 2015). Contudo, todo esse cenário não é aplicável às novas tendências do GP, como Kerzner (2015) argumenta, pois há um desafio de volume, variedade e velocidade das informações dentro do projeto, além do aumento da colaboração entre as pessoas.

Nach (2016) afirma que o GP atual, chamado de gerenciamento de projetos 2.0, considera tendências recentes em tecnologias baseadas em redes sociais e na Web 2.0, que auxiliam principalmente nas capacidades de comunicação e colaboração. Para Levine (2014), a gestão é uma atividade inerentemente social; logo, com a evolução das ferramentas da Web 2.0 tem-se uma atuação mais natural dentro dos projetos.

A gestão de projetos atual possui uma tendência ágil que tem como características equipes auto gerenciadas e com autonomia para tomar decisões; planejamento limitado; escopo mínimo com abertura para as mudanças; ênfase na velocidade; iterações de colaboração no trabalho; e envolvimento do cliente (Conforto, Salum, Amaral, da Silva, \& Almeida, 2014). Segundo Lorentz, Lima, Dias \& Guimarães 
(2014), emerge uma "nova" organização, por causa das reestruturações do contexto empresarial, logo essas transformações no ambiente organizacional obrigam os colaboradores a aparentar adaptabilidade. Além disso, existe hoje a necessidade de aceitação das constantes alterações das ferramentas tecnológicas no ambiente de trabalho, que requer mudanças nos processos, na estrutura e na cultura (Nach, 2016).

Considerando esta problemática, este artigo se propõe a responder: Quais são as características que devem ser consideradas no gerenciamento de projetos 2.0 ? Para tanto se conduziu uma pesquisa exploratória e qualitativa, considerando uma revisão sistemática da literatura, um grupo focal e um conjunto de entrevistas com profissionais de gestão de projetos de tecnologias de informação (TI).

\section{Referencial Teórico do gerenciamento de projetos 1.0 ao 2.0}

Conceitos tradicionais de amplitude de controle, relações de autoridade, hierarquia, além de especializações funcionais, geográficas e de produtos são características que têm se perpetuado na gestão de projetos. Ao longo da revisão da literatura foram ressaltadas algumas características do gerenciamento de projetos tradicional, apresentado neste trabalho como 1.0:

- Ordem e Disciplina (Hamel, 2009; Levitt, 2011): O GP foi historicamente desenvolvido com a suposição explícita de que os gerentes possuem o controle sobre a qualidade e a eficiência dos funcionários e das saídas produzidas por eles.

- Operacional (Atkinson, Crawford, \& Ward, 2006): Os passos são definidos pelos fluxos de processos, seguidos metódica e repetidamente, a burocracia é entendida como necessária, tudo é feito como e porque está no processo e as tarefas são executadas individualmente. Focado na elaboração de planos que determinam os pormenores que facilitarão 0 alcance dos objetivos do projeto $e$, consequentemente, da empresa.

- Top-Down (Levitt, 2011; Leybourne, Warburton, \& Kanabar, 2014): O locus de controle é hierárquico, refletido pelo organograma. A dinâmica institucional 
tradicional, incluindo as políticas, processos e práticas, está se transformando em um nível de fluidez de tempo real e dinamismo, baseado em pares, incluindo o aumento da proeminência de equipes de trabalho semi-autônomas.

- Centralização das Informações (Leybourne et al., 2014; McDonald, 2011; Hamel, 2009): Toda a comunicação é centralizada no gerente de projetos, com abordagem top-down, ou seja, inicia no gerente de projetos para os membros da equipe, em formato um para muitos.

- Ambiente previsível e estável (Leybourne et al., 2014): Baseado na disciplina e eficácia, por causa das condições relativamente estáveis na economia e na política, com tecnologias maduras, amplos recursos, clima previsível e sem grandes contingências. O planejamento é detalhado desde o início do projeto, tendo como necessidade a execução sem eventuais desvios da linha de base original. Em síntese, considera-se, portanto, que o gerenciamento de projetos clássico tem um estilo único e hierárquico, acompanhado de uma abordagem topdown e centralizada em relação ao planejamento e controle de projeto. Este paradigma se baseia no conhecimento explícito e documentado, ignorando, muitas vezes, o tácito que emerge das mudanças e das pessoas envolvidas no projeto. As categorias de características do gerenciamento de projetos contemporâneos, também chamados de 2.0, aqui apresentadas são resultado revisão sistemática da literatura (os procedimentos estão detalhados na metodologia do artigo).

- Autogestão e Autonomia das Pessoas: Com a redução de hierarquia, o trabalho se torna mais auto-organizado. A organização deve prover um clima que permita que os indivíduos e as equipes exerçam o seu próprio controle sobre os projetos e entregas. Esta característica tem como base os autores Hamel (2009), Levitt (2011), McDonald (2011), Palacios-Marqués, Cortés-Grao e Carral (2013) e Leybourne et al. (2014). 
- Colaboração: O gerenciamento de projetos 2.0 tem como atributo central a colaboração, segundo apontado por diversos autores (Filev, 2008; Hamel, 2009; Câmara, Soares, Tessi, \& Chaves, 2015; Lee, Reinicke, Sarkar, \& Anderson, 2015; Levitt, 2011; McDonald, 2011; Ollus, Jansson, Karvonen, Uoti, \& Riikonen, 2011; Leybourne et al., 2014). A troca de conhecimento facilita as conexões sociais dentro das empresas e fora delas também, tornando a resolução dos problemas mais rápida e mais produtiva, possibilitando entregas mais eficazes dos projetos. A colaboração é produzida em ambientes que contêm indivíduos com capacidade cognitiva para entender e alcançar conhecimentos trocados, e que existam conexões entre esses indivíduos.

- Comunicação Assíncrona e Não Hierárquica: A proposta desta categoria baseia-se em argumentos dos seguintes autores: Viguié, Zaraté e Soubie (2009), Levitt (2011), Ortiz-Marcos, Uruburu, Cobo e Prieto (2013) e Câmara et al. (2015). Com o forte impacto da cooperação em nível global, surge a necessidade de uma comunicação assíncrona, pois, por causa da distância, a comunicação não ocorre ao mesmo tempo, não é simultânea, sendo então a forma mais eficiente nesse contexto. Esse tipo de comunicação fortalece a não existência de hierarquia e/ou centralização das informações em apenas um tipo de pessoa, geralmente protagonizado pelo gerente de projetos. As informações começam a flutuar por todos os membros da equipe, não sendo necessário um "proxy" nas comunicações.

- Escopo Incremental e Mutável: A ampla definição de um projeto de forma abrangente e completa de uma única vez, durante o planejamento do projeto, é irrealista. Considerando esta questão, esta característica é baseada, principalmente, em argumentos de Levitt (2011) e Leybourne et al. (2014). Em ambientes voláteis, regido por mudanças, é necessário o incremento do escopo ao longo do projeto. Dentro de contextos dinâmicos, os requisitos mudam frequentemente, o que faz com que o escopo não seja fixo. Logo, necessita que o escopo seja mais ágil, com maior flexibilidade na absorção das mudanças e na capacidade de replanejar. 
- Trabalho com Equipes Virtuais: A discussão desta categoria é apresentada por diferentes autores (Filev, 2008; Viguié et al., 2009; Li, Ullrich, Helou, \& Gillet, 2010; Diviné, Schumacher, \& Cardinal, 2011; Levitt, 2011; McDonald, 2011; Ollus et al., 2011; Škrabálek, 2013; Palacios-Marqués et al., 2013; Jurina, Vrecko, \& Barilovic, 2014; Leybourne et al., 2014). A partir da globalização dos negócios, têm-se um crescimento de equipes de projetos caracterizadas como virtuais, possuindo membros em diferentes locais geográficos. Funciona como solução para tornar os projetos possíveis de serem executados, de forma remota. Envolve a necessidade de treinar e repassar informações de colaboração por meio da internet, envolvendo alto nível de compromisso, engajamento e motivação dos membros da equipe. A plataforma virtual elimina a tríplice dimensão: espaço, tempo e atividade, porém acarreta na introdução da multiculturalidade, conceituada pelas múltiplas culturas e tradições dentro dos projeto, aumentando a necessidade de utilizar a gestão em redes em substituição a tradicional estrutura hierárquica.

- Métodos Ágeis: Em contraste com o modelo tradicional de gerenciamento, o método fomenta a participação constante das partes interessadas dentro do projeto, em especial nas tomadas de decisões, ocasionando uma maior colaboração e eficiência na comunicação e ciclos curtos de entregas. Esta é uma categoria muito enfatizada por Levitt (2011) e Leybourne et al. (2014). Eles enfatizam que a disponibilidade contínua de uma entidade permite uma flexibilidade na rápida resposta a mudança.

- Tecnologia 2.0: Dado ao recente surgimento da Web 2.0, pode-se considerar que muitos são os trabalhos que apresentam a questão do uso de tecnologias colaborativas 2.0 em gestão de projetos (Filev, 2008; Viguié et al., 2009; Diviné et al., 2011; Li et al., 2010; Levitt, 2011; McDonald, 2011; Ollus et al., 2011; PalaciosMarqués et al., 2013; Ortiz-Marcos et al., 2013; Škrabálek, 2013; Jurina et al., 2014). Caracterizada pela colaboração usando a internet como plataforma, as ferramentas 2.0 trazem benefícios como redução da burocracia na comunicação e a fluidez da informação nas organizações. Facilita o trabalho remoto e as parcerias 
a nível mundial. As ferramentas colaborativas suportam as diferentes fases e atividades do GP.

Na Figura 1, Kerzner (2015) apresenta as principais diferenças entre o GP 1.0 e o gerenciamento de projetos contemporâneo, chamado por ele de 2.0.

\section{Tabela 1}

Diferenças entre o GP 1.0 e o GP 2.0

\begin{tabular}{l|l|l}
\hline \multicolumn{1}{c|}{ FATOR } & \multicolumn{1}{c}{ GP 1.0 } & \multicolumn{1}{c}{ GP 2.0 } \\
\hline $\begin{array}{l}\text { Processo de aprovação do } \\
\text { projeto }\end{array}$ & Envolvimento de GP mínima & Envolvimento de GP obrigatória \\
\hline Tipos de projetos & Operacional & Operacional e estratégico \\
\hline Planejamento & Centralizado & Descentralizado \\
\hline Requisitos do projeto & Bem definida & Evolutivo e flexível \\
\hline $\begin{array}{l}\text { Estrutura de divisão de } \\
\text { trabalho }\end{array}$ & Top down & Botton up \\
\hline Premissas e restrições & Fixas durante o projeto & Revalidadas ao longo do projeto \\
\hline Definição de sucesso & Tempo, custo e escopo & Valor criado \\
\hline Mudanças de escopo & Reduzido ao mínimo & Contínua \\
\hline Fluxo de trabalho - Atividade & Em série & Em paralelo \\
\hline Metodologias de GP & Rígido & Flexível \\
\hline Flexibilidade geral do projeto & Mínimo & Extenso, conforme a \\
necessidade
\end{tabular}

Autor: Adaptado de Kerzner (2015) 


\section{Metodologia}

Este estudo teve uma abordagem qualitativa. Inicialmente realizou-se uma revisão sistemática da literatura que identificou as características do gerenciamento de projetos 1.0 e 2.0. Esta revisão serviu de insumo para o grupo focal e para as entrevistas. As revisões sistemáticas da literatura procuram, considerando um protocolo, responder uma pergunta específica. No caso desta pesquisa foi: "Quais são as características do gerenciamento de projetos 2.0?"

Foram realizadas três buscas nas bases de dados: (1) "Project management 2.0": foram encontradas 155 publicações na ferramenta Publish or Perish/Google Scholar; (2) "Project management" and "Web 2.0": foram encontradas 22 publicações na Web of Science; (3) "Management 2.0": foram encontradas 8 publicações na Web of Science. Após este procedimento, foram retiradas publicações repetidas, que não foram encontradas para download ou que estão fora dos assuntos "Gerenciamento de Projetos" e "Web 2.0". Sendo assim, 23 publicações foram selecionadas para a leitura em profundidade. Os artigos foram armazenados na ferramenta Mendeley. Os dados relevantes dos artigos foram catalogados na ferramenta NVIVO, para a análise de conteúdo.

A segunda fase foi representada pela realização de um grupo focal exploratório, que teve duração de duas horas. Para este grupo focal foram selecionadas cinco pessoas, para assim poder garantir a participação de todos os presentes e manter o foco das discussões. Os critérios para seleção das pessoas foram: 1) trabalhar em cenários de projetos que utilizam tecnologias colaborativas (Web 2.0) e/ou métodos ágeis); 2) diferentes origens profissionais; e 3) equilíbrio de profissionais sênior e júnior. O áudio deste grupo focal foi transcrito para análise do conteúdo da discussão. Ao longo da sessão, os participantes partilharam suas visões e experiências, bem como registraram, espontaneamente, um resumo das características do gerenciamento de projetos 1.0 e 2.0 em um quadro em branco.

A última forma de coleta de dados foi a realização de um conjunto de entrevistas. Com base na revisão sistemática da literatura e os resultados do grupo focal exploratório, foi construído um roteiro semiestruturado com perguntas abertas. Foram realizadas 15 entrevistas com profissionais que trabalham na área de $\mathrm{Tl}$, de diferentes 
idades, de tempo de experiência, sexo e com posições de trabalhos diversas, que atuam em equipes de projetos no âmbito do gerenciamento de projetos 2.0. As entrevistas foram distribuídas entre 8 homens e 7 Mulheres, com idades entre 22 a 40 anos. As entrevistas tiveram duração média de 22 minutos. A seguir serão apresentadas as análises de todas as coletas de dados deste trabalho.

\section{Análise de dados}

Ao longo da coleta de dados procurou-se identificar as alterações entre a gestão de projetos 1.0 e a 2.0. Esta mudança fica evidente na fala de uma das entrevistadas com 20 anos de experiência na área de $\mathrm{Tl}$ e atualmente com cargo de gestão. A entrevistada afirma ter duas visões da gestão de projetos. Sobre a visão antiga ela diz que:

[E15] Gerenciar projetos para mim antes era fazer um método rodar e entregar um produto final. (...) tinha a visão do escopo bem definido, do que vai entregar, do plano do que a gente vai fazer, de acordo com o que foi planejado.

Diferente da definição anterior, para a mesma entrevistada o gerenciamento de projetos atualmente engloba o foco na entrega de valor, como também apontado no grupo focal exploratório. Os participantes do grupo focal consideram que 0 gerenciamento de projetos modernos tem como foco o que o cliente deseja.

[E15] Para mim hoje, gerenciar projetos é entregar valor. Muito mais importante que seguir um método é fazer com que as pessoas trabalhem para entregar um valor no final.

Ao longo das entrevistas, procurou-se identificar quais são as mudanças do GP 2.0. Os entrevistados consideram que o gerenciamento de projetos mudou ao longo dos últimos anos e que há novas características que compõem o GP 2.0:

[E15] Eu acho que o GP antes era muito voltado à contratação, controle e eu acho que o GP hoje é muito mais uma gestão de parceria e relacionamento.

Considerando a revisão sistemática da literatura sobre as características no GP 2.0, bem como elementos também identificados no grupo focal e nas entrevistas, serão apresentadas a seguir as características do gerenciamento de projetos 2.0. 
Sendo assim, esta análise está organizada nas sete características do GP 2.0 apresentadas na revisão da literatura.

\subsection{Pessoas}

Inicialmente, na revisão de literatura, esta categoria tinha o nome de "Autogestão e Autonomia das pessoas". Esta foi uma característica evidenciada no grupo focal e nas entrevistas, porém muitas outras foram destacadas sendo que se optou por ampliar o nome da categoria.

A primeira característica do gerenciamento de projetos 2.0 é o próprio perfil das pessoas que fazem parte das equipes. Uma entrevistada com atuação em gestão de grandes projetos e diferentes times globais aponta diferenças da nova geração:

[E11] (...) é um pessoal realmente muito jovem de 20, 23, 24 anos, e é outra cabeça, é um mindset muito diferente.

Com essas diferenças entre as gerações, percebe-se na fala dos entrevistados, principalmente dos gestores e líderes de equipes, que há um aumento na busca por colaboradores com características não restritamente técnicas, mas também avaliamse as competências pessoais:

[E08] O mercado tem procurado por pessoas que tenham um bom nível técnico, mas tenham também outras qualidades, como compromisso e comprometimento. Tem procurado por pessoas que têm o compromisso de entrega, se entende que aquela pessoa tem uma família e tal, mas ninguém trabalha até às 6 horas bate o ponto e vai embora. As pessoas ficam, porque tem entrega para fazer, porque o sprint está acabando e a gente tem que cumprir a sprint no fim de semana.

No grupo focal, a questão do novo perfil do colaborador também esteve presente. O participante 1 observa que as pessoas que atuavam no GP 1.0 receberam a tecnologia, enquanto as do 2.0 nasceram com a Web 2.0, fazendo com que os recursos humanos do 2.0 possuam mais posicionamento para tomada de decisão nos projetos. O participante 4 ressalta que ele, mesmo não tendo cargo de gestor, ganhou autonomia para tomar pequenas decisões no dia-a-dia. Os participantes destacaram, no contexto 2.0, a resiliência às mudanças, assim como a proatividade das pessoas. 
A questão das equipes exercerem o seu próprio controle esteve presente na discussão do grupo focal. Toda a responsabilidade do projeto no paradigma tradicional ficava centralizada com o GP e esse gestor não tinha o feedback dos recursos do projeto, o que é diferente no GP 2.0, principalmente com a inserção dos métodos ágeis e tecnologias da Web 2.0, que facilitaram a troca e divulgação das informações do projeto. O participante 1 destaca que no $1.0 \circ \mathrm{GP}$ tinha muito controle, que era obrigado a ter a visão do todo, somente ele, então todo o fluxo do projeto era "top guela down". O participante 3 relembrou um projeto 1.0 em que o GP não conversava com a equipe, que ele vivia em um "aquário" fechado com papéis, gráficos, mas sem nenhum feedback das pessoas para falar sobre a visão do projeto.

Outra questão que apareceu ao longo de algumas entrevistas é a desvinculação da formação do profissional a uma determinada empresa.

[E07] Antigamente tinha muito aquela visão de entrei no primeiro emprego e vou aposentar no primeiro emprego. (...) então as pessoas estavam ali e morriam ali, tinha uma "carreira".

Esta nova postura acaba por ocasionar rotatividade nas equipes, pois as pessoas estão em busca de evolução na carreira. No geral, segundo os entrevistados, as pessoas que compõem as novas gerações estão em busca de realização, não necessariamente de dinheiro, como exemplifica o entrevistado E01, de 27 anos.

Eu gosto muito do que eu faço (...). Ah, eu vou trabalhar de boa, vamos trabalhar até mais tarde, vamos virar, vamos trabalhar no fim de semana, vou, nunca me incomodei, porque eu gosto do que eu faço. O que sempre me preocupa é o bem-estar, isso está até mais forte na geração dos mileniums.

\subsection{Colaboração}

Todos os entrevistados participam de projetos que possuem uma "miscelânea" de gerações envolvidas. Segundo eles, cada vez mais as equipes estão incluindo membros de gerações mais novas, que possuem mais acesso às informações, isto em todo o seu desenvolvimento como pessoa, o que fortalece a colaboração nos projetos e desinibição dos recursos humanos: 
[E11] É uma coisa bem importante, porque se vocês tem dúvida de alguma coisa, vocês rapidamente abrem o celular e 'oh tá aqui oh, é mentira, é verdade'.

[E15] Eu acho que a geração atual com relação a geração anterior, ela é mais independente, ela é mais auto suficiente, eles sabem mais assim, eles participam mais, têm mais ideias críticas.

Os participantes 1, 3 e 5 do grupo focal enfatizaram várias vezes o destaque da colaboração nos novos projetos e que os recursos humanos do GP 1.0 eram de uma geração diferente, que possuíam maior preocupação em fazer e entregar os seus pacotes de trabalho do que em colaborar, mesmo sabendo que o projeto teria insucesso por isso.

\subsection{Comunicação Assíncrona e Não Hierárquica}

A comunicação dos projetos modernos mudou muito, segundo os entrevistados: estão mais intensas, frequentes e mais virtuais:

[E03] Eu acho que os projetos atualmente têm muito mais comunicação, talvez antes demorava mais para uma pessoa saber que deu erro ali. Comunicar a outra pessoa, dizer 'oh isso aqui não está certo, vamos mudar, fazer de outra maneira'.

[E01] Eu acho que não, principalmente na parte de comunicação eu acho que mudou bastante, você meio que fica obrigado a estar 24 horas por dia se comunicando. As vezes de madrugada tem alguém do time mandando report.

No grupo focal destacou-se que a responsabilidade da comunicação do projeto ficava centralizada com o gerente do projeto e esse gestor não tinha o feedback dos recursos do projeto, o que é diferente no GP 2.0, principalmente com a inserção dos métodos ágeis e tecnologias da Web 2.0, que facilitaram a troca e divulgação das informações do projeto.

As equipes utilizam cada vez mais as ferramentas baseadas na internet e colaborativas para a comunicação e gestão de projetos (Gibson \& Cohen, 2003): 
[E02] Muito e-mail e as ferramentas mais verbal, como são, é muito raro ser uma equipe que esteja presente fisicamente, então é telefone, Skype e Whatsapp com pessoas que estão fora do país.

Os entrevistados apresentam seus receios de vulgarizar a comunicação com as novas tecnologias colaborativas:

[E09] A comunicação é um negócio de muita preocupação, porque vou ser bem sincero, a facilidade da tecnologia para a comunicação banaliza a comunicação mesmo e aí acaba desvirtuando. (...) E acho que com essas novas tecnologias de comunicação a gente tem que manter o mesmo cuidado que tinha antigo com o e-mail (...). Em todos os lugares utilizamos a mesma regra, o que diferencia é que precisa saber o momento de usar cada um, aí é onde tem que saber ganhar o jogo.

\subsection{Escopo Incremental e Mutável}

Em relação ao escopo incremental e mutável dos projetos, questões emergiram tanto nas entrevistas quanto no grupo focal. Os entrevistados ressaltam que as mudanças sempre aconteceram nos projetos, porém no gerenciamento de projetos 1.0 era tratado, como explicitado no grupo focal, somente no fim do projeto, pois era quando tinha-se a descoberta. Atualmente a mudança está intrínseca nos projetos e é item fundamental em uma gestão de projetos:

[E02] E ser capaz de lidar com as mudanças e conseguir orientar as equipes durante essas mudanças.

[E07] (...) é mitigar risco, conseguir alocação de recurso no tempo necessário e no custo necessário. O que mais impacta pra mim é risco que não é mitigado no começo e recurso que não é infinito. $O$ resto faz parte do dia-a-dia e a gente descobre com o andamento dele.

Esta questão da mudança ao longo do projeto também foi enfatizada no grupo focal. Destacaram que não é porque os métodos ágeis são mais rápidos nas respostas ao contexto e nas entregas que não há documentação ou organização no replanejamento do projeto; ao contrário, o foco do projeto agora é o que o cliente deseja. Para o participante 1, a dificuldade existe em achar um ponto de equilíbrio entre 1.0 e $\circ 2.0$, pois quem compra o projeto está pensando no 1.0, com foco no 
quando irá entregar tudo pronto, enquanto na execução é 2.0, com entregas fracionadas, sem o foco na data final, mas sim na melhor entrega possível contemplando as mudanças que ocorrem.

\subsection{Trabalho com Equipes Virtuais}

Dos 15 entrevistados, somente 05 não trabalham com atividades remotas, ou seja, não possuem equipes virtuais. Para os entrevistados com as equipes virtuais, aumentou a necessidade de disponibilidade das pessoas, por causa das diferenças de horário de trabalho e da acessibilidade/facilidade das ferramentas colaborativas conectadas a internet:

[E01] Não está mais dentro daquele período que você está ali alocado dentro da empresa. As pessoas estão em vários locais, em locais diferentes do mundo, com horários de trabalho diferenciados, que as vezes conflita com seu horário de descanso. E ai você acaba exercendo nesse período um pouco do trabalho.

As equipes virtuais são caracterizadas pelo trabalho a distância, porém com esforço em conjunto em prol de um objetivo:

[E02] Trabalho com essas pessoas como se trabalhasse no mesmo escritório, montamos um webx e fazemos uma conferência, está todo mundo vendo a mesma tela, todo mundo vendo a apresentação, discutimos, faz acessos, é justamente para que sejam naturais, não tem uma diferença pelos fatos das ferramentas.

Uma das preocupações observadas pelos entrevistados é com a comunicação que é essencial em qualquer ambiente, virtual ou presencial, que seja eficaz:

[E01] Existem $\mathrm{n}$ canais de comunicação que as pessoas utilizam, então a comunicação mudou bastante nesse ponto. (...). Com equipes virtuais você tem que tentar elucidar o melhor possível, porque se não se estende muito a conversa. 


\subsection{Uso de Métodos Ágeis}

Dos 15 entrevistados apenas 4 não trabalham com algum método ágil, porém atuam com ferramentas colaborativas. Os entrevistados consideram que uma das grandes mudanças no GP moderno são os métodos ágeis, pois há clientes que exigem a gestão de projetos ágil em seus contratos de TI:

[E11] Existem clientes que só aceitam trabalhar com a gente hoje com métodos ágeis. Então é muito interessante, porque realmente a equipe se vê como única.

[E08] Eu identifico uma crescente necessidade de tornar cada vez mais dentro das metodologias ágeis. A vantagem de usar métodos ágeis é de errar mais cedo, corrige mais cedo e também mostra valor para o demandante do projeto.

Entrevistados com diferentes idades e posições de trabalho apresentaram posicionamentos parecidos sobre os métodos ágeis:

[E12] Com certeza todo ano as coisas estão mudando. O que mais vi no gerenciamento de projetos é a grande tendência ágil. Não existe mais aquela coisa engessada, que devemos seguir o PMBoK.

Os entrevistados deixam evidente que os métodos ágeis são utilizados conforme necessidade dos times e dos projetos:

[E12] Utilizamos técnicas ágeis que são adaptadas a nossa realidade.

[E04] A gente adaptou o scrum a nossa realidade, basicamente. (...). Adapta as nossas necessidades.

Vale ressaltar não somente a importância de adaptar os métodos ágeis mais adequados às necessidades dos projetos e das empresas, mas também a necessidade de saber mesclar boas práticas também não ágeis:

[E09] Eu gosto de uma mescla dos dois na verdade, tradicional e ágil, eu tenho visões de agilidade, mas eu tenho uma visão de longo prazo, isso na minha opinião está funcionando bem, principalmente quando a gente fala de projetos de $\mathrm{TI}$, onde é difícil mesmo, tem que ser ágil no desenvolvimento com o pessoal técnico e ao mesmo tempo eu preciso dar uma visibilidade para o cliente de longo prazo.

Finalmente, no grupo focal, o participante 5 considera que a maior preocupação em relação ao ágil é para que o método não se torne superficial, pois no intuito de ser 
ágil as pessoas, se não forem bem conduzidas, podem se perder e deixar o projeto escorregar não tendo controle de todas as mudanças. Ele conclui que há uma preocupação do que será perdido do que já havia sido construído no 1.0, em relação à arquitetura de robustez na base de tudo que era feito, como por exemplo no controle rígido de documentação. Os participantes 2 e 3 ressaltam que a discussão relacionada aos métodos ágeis está sempre em torno da documentação, mas que não há nenhuma disputa, pois os ágeis não abonam documentação, apenas focam em fazer a documentação necessária, o que realmente será útil para o projeto. E o participante 5 finaliza levantando novamente a preocupação entre o equilíbrio do que é burocracia e o que é essencial, complementado pela preocupação do participante 4 de que na vontade de fazer rápido tudo se perca, havendo necessidade de separar o que é ágil e o que é rápido.

\subsection{Tecnologia 2.0}

A outra grande característica do GP 2.0 elencada pelos entrevistados são as ferramentas colaborativas ou 2.0, bem como sua implicação nas novas formas de comunicação:

[E03] Com certeza acho que tem diferenças entre a gestão antiga e a atual. Acho que a principal é a tecnologia, mas também o modo como gerenciava antigamente não acho que funciona hoje em dia.

Ao longo da fala dos entrevistados fica evidente que muitas são as mudanças experimentadas pelas pessoas, ocasionadas por elementos do dia-a-dia, como a tecnologia com que se trabalha:

[E15] Eu acho que de acordo com a tecnologia o perfil vai mudando. Assim as gerações são diferentes com certeza, é que eu acho que os perfis variam muito de acordo com os projetos em que trabalha. Eu percebo que o pessoal que trabalha mais com banco de dados é um pouquinho mais introspectivo, isso era antes e continua sendo agora, não consigo ver uma evolução nesse sentido.

Ferramentas Web 2.0 são essenciais nos projetos em que os entrevistados participam: 
[E11] Se não fossem todas essas ferramentas, seria impossível fazer o acompanhamento de um projeto e realmente poder entender como que está o status de cada operação ou projeto. A gente utiliza também muitas ferramentas de desenvolvimento colaborativo, (...) que permitem você ver exatamente em tempo real o andamento de um determinado desenvolvimento de código.

No grupo focal o participante 4 destacou a flexibilidade que essas ferramentas oferecem no dia-a-dia, principalmente no ambiente em que ele atua, pois ele pode participar de uma reunião mesmo estando em home office, assim como melhora a velocidade da troca de informações e dados, e também diminui a distância com os clientes.

\section{Considerações finais}

O ambiente mais volátil, em constante mudança, fez com que o gerenciamento de projetos se adaptasse a essas mudanças, para atender às novas necessidades. A tecnologia colaborativa influencia diretamente na gestão atual, como também os métodos ágeis e os recursos humanos que cresceram com a internet.

A partir do resultado da revisão sistemática, do grupo focal e das entrevistas, que tiveram o objetivo de identificar as características do gerenciamento de projetos 2.0, observa-se uma expansão do gerenciamento de projetos para se adaptar às novas necessidades emergentes. Um conjunto de particularidades do gerenciamento de projetos moderno foi apresentado, dentre elas estão: a comunicação descentralizada, a organização delineada em rede, em vez da forte estrutura hierarquia burocrática, o projeto com escopo flexível e incremental para absorver as mudanças oriundas de mercados e negócios dinâmicos, globais e velozes, além dos modelos de trabalho cada vez mais virtuais e um novo perfil dos recursos humanos e o entendimento destes sobre o trabalho. Percebeu-se então que o gerenciamento de projetos 2.0 tem como desafio estimular uma nova geração que privilegia a interação sensorial, vivida na internet e alfabetizada com a web, e que possui novas exigências (como ambientes de trabalho "divertidos") e possui competências diferenciadas.

Constata-se uma expansão do gerenciamento de projetos, de organização temporária a tripé fundamental para a execução da estratégia organizacional. 
gerenciamento de projetos 2.0 baseia-se em um novo paradigma da era da informação global.

As contribuições deste estudo foram em âmbito teórico, com a exploração em profundidade das características do gerenciamento de projetos moderno, porém considera-se que o tema encontra-se na sua infância, exigindo muito esforço da academia nos próximos anos. Finamente, ressalta-se que as características aqui apresentadas devem ser levadas em consideração pelos praticantes no momento da elaboração e gerenciamento dos projetos 2.0.

Este tema, o gerenciamento de projetos 2.0, ainda é pouco explorado na literatura, contudo ao longo do trabalho foi percebido que os praticantes já têm estes conceitos muito claros, vividos nas suas atividades cotidianas. Sugere-se como estudos futuros a condução de grupos focais confirmatórios e também a criação de modelos quantitativos para validação das características aqui apresentadas.

\section{Referências}

Atkinson, R., Crawford, L., \& Ward., S. (2006). Fundamental uncertainties in projects and the scope of project management. International Journal of Project Management, 24(8), 687-698.

Câmara, R., Soares, R., Tessi, M., \& Chaves, M. S. (2015). WikiRiskMan: Um Framework para Gestão de Riscos em Projetos. Americas Conference on Information Systems (AMCIS), Puerto Rico.

Cicmil, S., Williams, T., Thomas, J., \& Hodgson, D. (2006). Rethinking Project Management: Researching the actuality of projects. International Journal of Project Management, 24(8), 675-686.

Conforto, E. C., Salum, F., Amaral, D. C., da Silva, S. L., \& de Almeida, L. F. M. (2014). Can agile project management be adopted by industries other than software development?. Project Management Journal, 45(3), 21-34.

Diviné, M., Schumacher, M., \& Stal-Le Cardinal, J. (2011). Learning virtual teams: how to design a set of Web 2.0 tools?. International Journal of Technology Management, 55(3/4), 297-308.

Filev, A. (2008). Project Management 2.0: The Ultimate Benefits of the New Approach to Project Management. PM World Today, 10.

Hamel, G. (2009). Moon shots for management. Harvard Business Review, 87(2), 91 98. 
Jurina, K., Vrecko, I., \& Barilovic, Z. (2014). Web Technologies Development Supporting Contemporary Project Management Needs. Interdisciplinary Management Research, 10, 69-76.

Kerzner, H. (2015). Project Management 2.0. John Wiley \& Sons.

Lee, L., Reinicke, B., Sarkar, R., \& Anderson, R. (2015). Learning Through Interactions: Improving Project Management Through Communities of Practice. Project Management Journal, 46(1), 40-52.

Levine, A. (2014). Social Networking Tools: An Introduction to Their Role in Project Management. In P. Dinsmore \& J. Cabanis-brewin (Eds.), The AMA Handbook of Project Management (4th ed.). American management Association.

Levitt, R.E. (2011) Towards project management 2.0. Engineering Project Organization Journal, 1(3), 197-210.

Leybourne, S. A., Warburton, R., \& Kanabar, V. (2014). Is project management the new management 2.0?. Organisational Project Management, 1(1), 16-36.

Li, N., Ullrich, C., El Helou, S., \& Gillet, D. (2010). Using social software for teamwork and collaborative project management in higher education. In Advances in WebBased Learning-ICWL 2010 (pp. 161-170). Springer Berlin Heidelberg.

Lorentz, C. N., de Lima, L. C. C., Dias, B. O. S. V., \& Guimarães, L. D. V. M. (2014). Subjetividade e Identidade dos Gerentes frente aos Novos Papéis Exigidos no Atual Contexto Organizacional. Revista Gestão \& Tecnologia, 14(3), 219-243.

McDonald, P. (2011). It's time for management version 2.0: Six forces redefining the future of modern management. Futures, 43(8), 797-808.

Nach, H. (2016). Project Management 2.0: Towards the Renewal of the Discipline. Strategic Integration of Social Media into Project Management Practice, 1-15.

Ollus, M., Jansson, K., Karvonen, I., Uoti, M., \& Riikonen, H. (2011). Supporting collaborative project management. Production Planning \& Control, 22(5-6), 538553.

Ortiz-Marcos, I., Uruburu, C. A., Cobo, B. J. R., \& Prieto, R. T. (2013). Strengthening communication skills in an innovative context of engineering project management learning. Procedia-Social and Behavioral Sciences, 74, 233-243.

Palacios-Marqués, D., Cortés-Grao, R., \& Carral, C. L. (2013). Outstanding knowledge competences and web 2.0 practices for developing successful e-learning project management. International Journal of Project Management, 31(1), 14-21.

PMI - Project Magement Institute. (2013) A Guide to the Project Management Body of Knowledge - PMBOK® Guide 5 Edition, Pennsylvania, USA. 
Shenhar, A. J. (2004). Strategic Project Leadership $®$ Toward a strategic approach to project management. R\&D Management, 34(5), 569-578.

Skrabálek, J. (2013). Why Modern Mobile and Web-Based Development need a Lean Agile Web Approach (LAWA).

Viguié, P., Zaraté, P., \& Soubie, J. L. (2009). Designing collaboration on a microsoft WSS platform: A relevant Web-Parts choice. 13th International Conference on Computer Supported Cooperative Work in Design. (570-575). IEEE. 